Article

\title{
A Comparative Study of Fungal Community Structure, Diversity and Richness between the Soil and the Phyllosphere of Native Grass Species in a Copper Tailings Dam in Shanxi Province, China
}

\author{
Tong Jia ${ }^{*}{ }^{\dagger}$, Ruihong Wang ${ }^{\dagger}$, Xiaohui Fan and Baofeng Chai \\ Institute of Loess Plateau, Shanxi University, Taiyuan 030006, China; 15103407095@163.com (R.W.); \\ finexiaohui@163.com (X.F.); bfchai@sxu.edu.cn (B.C.) \\ * Correspondence: jiatong@sxu.edu.cn; Tel.: +86-155-1369-4458 \\ + These authors contributed equally to this work.
}

Received: 20 July 2018; Accepted: 2 August 2018; Published: 3 August 2018

\begin{abstract}
In the study area, mining processes have led to the accumulation of a large amount of ore sand and a tailings dam was established above this artificial overburden. After a long period of restoration, the area was reclaimed by a variety of native vegetation. This study investigated four of these native grass species, namely, Bothriochloa ischaemum, Imperata cylindrica, Elymus dahuricus and Calamagrostis epigejos, having reestablished themselves after the restoration of a copper tailings dam built in 1969 in Shanxi Province, China. We analyzed the fungal community structure in the soil and the phyllosphere of the four native grass species using high-throughput sequencing. Results showed that the soil of the tailings dam was weakly alkaline and copper $(\mathrm{Cu})$ was the most pervasive element present. Ascomycota were the dominant fungal taxa in the soil and the phyllosphere of all four native grass species, for which total soil nitrogen $(\mathrm{N})$ content was an influencing factor. Basidiomycota was positively correlated to cadmium (Cd), which can additionally be used as an indicator of $\mathrm{Cd}$ pollution in copper tailings dams. Among the four native grass species, Nectriaceae was the dominant fungal family found exclusively in B. ischaemum; Meruliaceae and Phaeosphaeriaceae were the dominant fungal families of E. dahuricus; Cordycipitaceae and Sporormiaceae were only found in C. epigejos. However, we found no evidence of a dominant fungal family in I. cylindrica. Furthermore, Erythrobasidiales sp., which had the highest betweenness centrality after network analysis, was identified as the key fungal species in all four native grass species.
\end{abstract}

Keywords: copper tailings dam; native grasses; phyllosphere fungi; soil fungal community

\section{Introduction}

As the basis of agricultural production and productive resources, soil is an agent of plant growth. Soil moisture and nutrients necessary for plant growth are absorbed by roots. Soil microorganisms are the principal decomposers of plant, litter, and animal residue and they play a major role in the native cycle of matter and the transformation of soil organic matter (SOC) and inorganic matter [1]. At the same time, fungi play an important role in soil microbial communities and are involved in a variety of functions associated with soil ecosystems [2]. For example, being an important member of the soil microbial community, soil fungi in conjunction with other microorganisms participate in the material circulation and energy flow of ecosystems [3]. Additionally, soil fungi also take part in soil humification and mineralization processes and they play a significant role in the formation of humus and soil granular structure. Soil fungi also participate in the nutrient cycle and are one of the basic components of the ecosystem food chain, from which other organisms form mutually 
beneficial, symbiotic or competitive relationships [4]. Finally, soil fungi are the main participants in nutrient transformation [5], being the interface between water membrane biota and bacteria, protozoa, and nematodes in soil [6]. Additionally, fungi usually form symbiotic relationships with higher plant species to provide nutrients for plant growth, while pathogenic fungi also affect forest health [7].

Plants, being an important component of the biosphere, have a significant impact on the stability and coordinated development of the entire ecosystem [8]. The composition and variation of plant communities also have a direct impact on the diversity of soil microorganisms [9]. Being an important component of plants, leaves are also an important carrier for plant microbial subsistence. The phyllosphere is a unique habitat, providing rich microbial diversity and being the main plant habitat for microbes, offers a better living environment for microbial colonization. At the same time, the microbial community of the phyllosphere is vital in protecting host plants from pathogens [10]. However, the phyllosphere is a harsh environment for microbes, namely, it provides limited nutrition, considerable diurnal and nocturnal temperature differences, and significant fluctuations in humidity. In addition, the strong ultraviolet radiation that the phyllosphere is subject to has a significant influence on the survival of phyllosphere microbial communities. Nevertheless, phyllosphere microbial communities are composed of an abundance of species that include bacteria, filamentous fungi, yeast, algae, and a small number of nematodes and protozoa [11]. Over the past several decades, research related to phyllosphere microbial communities have focused on culturable species, pathogens, and beneficial microorganisms associated with host plants [12].

The copper mine selected for this study, located in Yuanqu County, Shanxi Province, is the largest underground mine of its type in China. The main mineral resource of this mine is copper $(\mathrm{Cu})$ and to a lesser degree, cobalt $(\mathrm{Co})$, molybdenum $(\mathrm{Mo})$, gold $(\mathrm{Au})$, and silver $(\mathrm{Ag})$, as well as other metals [13]. A great deal of ore sand has been produced in the process of mining and the tailings dam formed from this ore sand has increased over time. Following restoration, plants began to reclaim this tailings dam. Bothriochloa ischaemum (L.) Keng is the dominant plant species, while Imperata cylindrica (L.) Beauv., Elymus dahuricus Turcz., Calamagrostis epigejos (L.) Roth, and Poa annua L. are secondary species. Variation of bacterial communities in the soil of tailings dams and the diversity of endophytic fungi used by native grass species have already been reported on $[13,14]$. However, few studies to date have reported on the characteristics of soil fungi and native grass species as they relate to phyllosphere fungi. Therefore, we selected reparative vegetation associated with copper tailings dam soil remediation processes as our research object and we discuss issues related to this heavy metal polluted environment. The objectives of this study were (1) to ascertain the structural characteristics of soil fungi and the phyllosphere fungal community; (2) to establish the relationship between the structure and function of fungal communities and environmental factors; and (3) to determine the effects that certain fungal communities have on heavy metal pollution. By exploring relationships among fungal communities in a copper tailings dam, this study aims to provide a scientific basis for screening heavy metal tolerant microbial strains for the ecological restoration of mining sites to help improve the efficiency of ecological remediation.

\section{Materials and Methods}

\subsection{Site Description}

The experimental site is located in Yuanqu County, Shanxi Province, China. The mean annual temperature is $13.5^{\circ} \mathrm{C}$, the mean annual precipitation is $631 \mathrm{~mm}$ and the mean annual relative humidity is 63\%. The 'eighteenth' river tailings of the Northern Copper Mine were established in 1969 [15]. The tailings dam is located at the mouth of the mine and forms a trapezoidal shape. The dam was heaped into its present shape through artificial methods, for which the ore and ore sand were pushed near the tailings at the front of dam before being compacted by mechanical rolling. The main components of the tailings dam are tailings soil, tailings sand, and artificially covered loess. At present, B. ischaemum is the dominant plant species in the sub-dams constructed throughout different restoration years. 


\subsection{Research Methods}

The following subsections discuss the research methods used for this study.

\subsubsection{Sample Collection}

We selected a sub-dam built in 1969 for this study, which was conducted in July 2016 by collecting soil and leaf samples for analysis. Five replicate plots were established along a transect line at each sampling site. Five soil samples were collected from each plot within the 0 to $10 \mathrm{~cm}$ soil layer using a sterile auger, after which the samples were mixed in plastic bags to form composite samples and kept on ice during transport to the laboratory. Samples were sieved through a $4 \mathrm{~mm}$ mesh in order to remove plant debris and roots. We collected samples from B. ischaemum, I. cylindrica, E. dahuricus and C. epigejos. Fully-expanded leaves of these four plant species were randomly selected from 16 individuals. They were then stored on ice and transported to the laboratory. Some soil samples were placed in a refrigerator at $4{ }^{\circ} \mathrm{C}$ before being analyzed and measured to determine their physical and chemical properties. The other samples, including plant leaves, were placed in a freezer at $-20^{\circ} \mathrm{C}$ to use for genome extraction and high-throughput sequencing.

\subsubsection{Soil Physical and Chemical Properties}

We measured soil $\mathrm{pH}$ after shaking the soil water (1:2.5 mass/volume) suspensions for $30 \mathrm{~min}$. Soil moisture was measured gravimetrically. We measured soil particle size (PS) using a Mastersizer 3000 laser diffraction particle size analyzer (Malvern Co., Ltd., Malvern, UK). Before obtaining the particle size measurements, however, each sample was weighed $(3 \mathrm{~g})$ and sediments were first immersed in $10 \% \mathrm{H}_{2} \mathrm{O}_{2}$ and then in $12.7 \% \mathrm{HCl}$ to remove any plant debris and to disperse aggregates within the sediments. The final procedure was to treat sample residue with $10 \mathrm{~mL}$ of $0.05 \mathrm{M}\left(\mathrm{NaPO}_{3}\right)_{6}$ in an ultrasonic vibrator for $10 \mathrm{~min}$ to facilitate dispersion prior to particle size analysis. Note that we only found slight differences $(0.5 \%)$ in the samples throughout our repeated particle size measurements. We measured total soil carbon (TC), total nitrogen (TN), and total sulfur (TS) content using an elemental analyzer (vario EL/MACRO cube, Elementar, Hanau, Germany). Additionally, we measured soil ammonium nitrogen $\left(\mathrm{NH}_{4}{ }^{+}-\mathrm{N}\right)$, nitrate nitrogen $\left(\mathrm{NO}_{3}{ }^{-}-\mathrm{N}\right)$, nitrite nitrogen $\left(\mathrm{NO}_{2}{ }^{-}-\mathrm{N}\right)$, and Olsen $\mathrm{P}$ using an automated discrete analyzer (CleverChem 380, DeChem-Tech. GmbH, Hamburg, Germany). Heavy metal elements, including arsenic $(\mathrm{As})$, cadmium $(\mathrm{Cd}), \mathrm{Cu}$, lead $(\mathrm{Pb})$, and zinc $(\mathrm{Zn})$ were measured after shaking in a reagent $\left(3.0 \mathrm{~mL} \mathrm{HNO}_{3}, 1.0 \mathrm{~mL} \mathrm{HF}\right.$, and $\left.2.0 \mathrm{~mL} \mathrm{H}_{2} \mathrm{O}_{2}\right)$ and allowed to settle for $30 \mathrm{~min}$ before microwave digestion. Samples were measured by inductively coupled plasma-atomic emission spectrometry (iCAP 6000, Thermo Fisher, Cambridge, UK).

\subsubsection{DNA Extraction and High-Throughput Sequencing of Soil and Phyllosphere Samples}

The sequencing and extraction of total soil microbial DNA was conducted at the Shanghai Personal Biotechnology Limited Company using the EZNA Soil DNA Kit (Sangon Company, Shanghai, China). We did the amplification of the ITS1 region with ITS1F (5'-TCCGTAGGTGAACCTGCGG-3') and ITS2R (5'-GCTGCGTTCTTCATCGATGC-3') primers. Similarly, the sequencing and extraction of total leaf microbial DNA of the four native grass species was conducted at Shanghai Biozeron Co., Ltd. (Shanghai, China), and the total leaf microbial DNA using the EZNA Soil DNA Kit (Omega Bio-Tek, Inc., Norcross, GA, USA). Amplification of the 18s RNA gene is an ITS1 fragment with ITS1F (5'-GTTGGTCATTTAGAGGAAGTAA-3') and ITS2R (5'-GCTGCGTTCTTCATCGATGC-3') as primers.

\subsection{Statistical Analysis}

Soil physical and chemical properties, including TN, TC, TS, $\mathrm{NH}_{4}{ }^{+}-\mathrm{N}, \mathrm{NO}_{3}{ }^{-}-\mathrm{N}, \mathrm{NO}_{2}{ }^{-}-\mathrm{N}$, soil water content (SWC), particle size (PS), Olsen $\mathrm{P}, \mathrm{pH}$ and heavy metal content, were analyzed using $\mathrm{R}$ 3.3.1 (64 bit). The composition datum of soil fungi and phyllosphere fungal communities in the native grass species was analyzed using Microsoft Excel 2010. The rarefaction analysis based on Mothur 
v.1.21.1 [16] was conducted to reveal the alpha diversity indices (Shannon index, Simpson index) [17] and richness estimators [abundance-based coverage estimator (ACE index) and Chao1 index] [18]. Principal component analysis (PCA) was used to analyze the relationships between soil fungi and environmental factors. Principal coordinates analysis (PCoA) was used to analyze phyllosphere fungi from similar sources. Both PCA and PCoA were conducted using CANOCO 5.0. Gephi was used to analyze the relationships among phyllosphere fungi and statistical analysis was conducted using SPSS 13.0 and Excel 2010 (Redmond, WA, USA).

\section{Results}

\subsection{Soil Physicochemical Properties}

Results showed that soil $\mathrm{pH}$ was weakly alkaline (7.9), with an average soil PS of $37.34 \mu \mathrm{m}$ (Figure 1). Soil TC was higher than both TN and TS, with values of $17.12 \mathrm{~g} \cdot \mathrm{kg}^{-1}, 0.69 \mathrm{~g} \cdot \mathrm{kg}^{-1}$ and $0.99 \mathrm{~g} \cdot \mathrm{kg}^{-1}$, respectively. $\mathrm{NO}_{3}{ }^{-}-\mathrm{N}$ and $\mathrm{NO}_{2}{ }^{-}-\mathrm{N}$ played an important role in nitration, with values of $5.12 \mathrm{mg} \cdot \mathrm{kg}^{-1}$ and $0.39 \mathrm{mg} \cdot \mathrm{kg}^{-1}$, respectively. Conversely, $\mathrm{NH}_{4}{ }^{+}-\mathrm{N}\left(8.49 \mathrm{mg} \cdot \mathrm{kg}^{-1}\right)$ played a key role in denitrification. Available phosphorus $(\mathrm{P})$ was an important indicator of soil $\mathrm{P}$ content and Olsen P was $7.21 \mathrm{mg} \cdot \mathrm{kg}^{-1}$ in our study (Figure 1A). Different heavy metals were found in the soil of the tailings dam, Cu content being the highest $\left(553.53 \mathrm{mg} \cdot \mathrm{L}^{-1}\right)$, followed by As and $\mathrm{Cd}\left(9.61 \mathrm{mg} \cdot \mathrm{L}^{-1}\right.$ and $5.27 \mathrm{mg} \cdot \mathrm{L}^{-1}$, respectively) (Figure $1 \mathrm{~B}$ ).
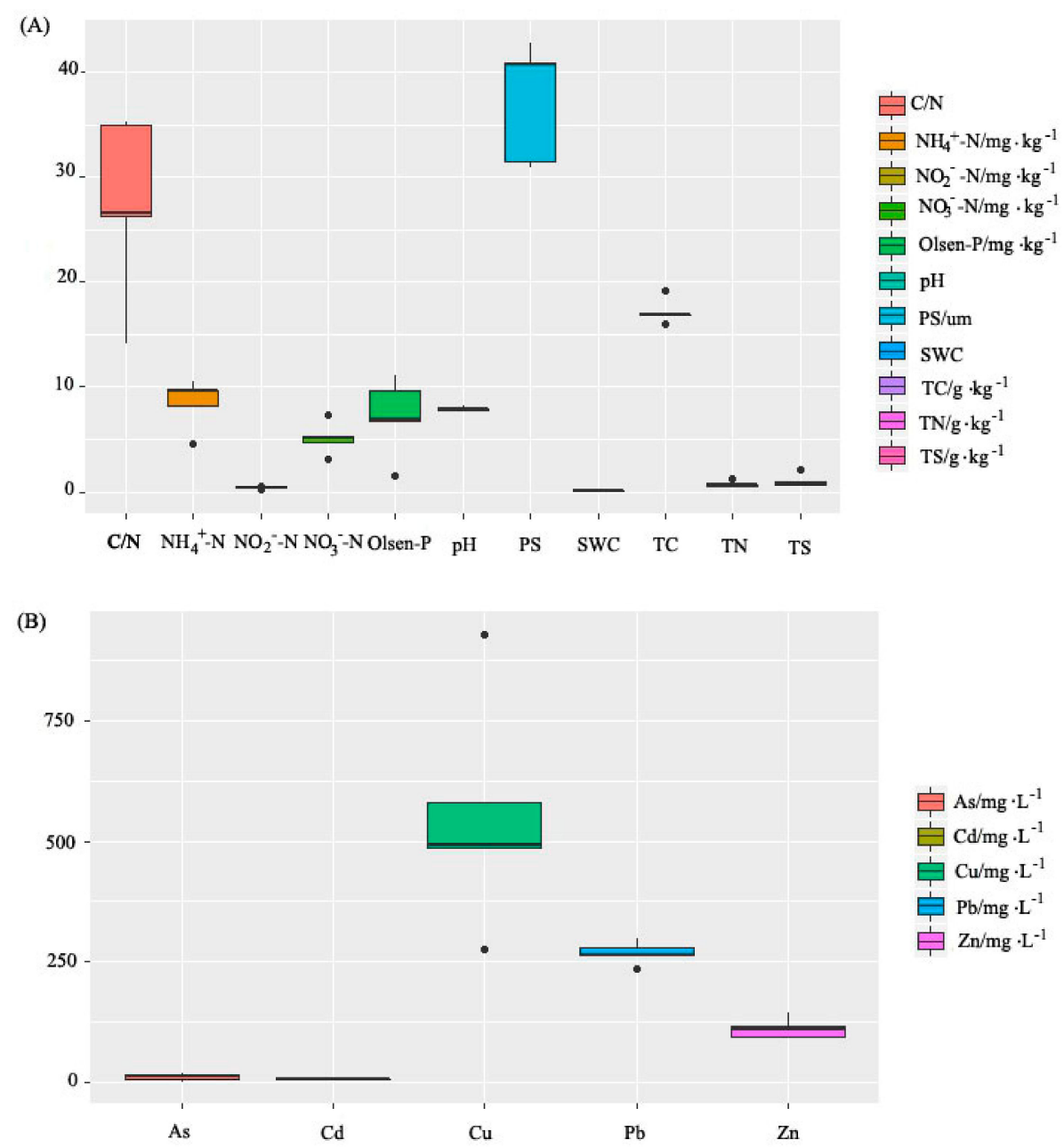

Figure 1. Soil physicochemical properties under copper tailing dam; (A) soil chemical properties, (B) the content of heavy metal in soil. 


\subsection{Community Composition of the Soil and Phyllosphere}

\subsubsection{Soil Fungal Communities}

Soil fungal community composition was composed of four fungal phyla: Ascomycota, Basidiomycota, Chytridiomycota and Zygomycota. Ascomycota (58.20\%) had the highest relative abundance and was the dominant phylum, followed by Basidiomycota (2.79\%), Zygomycota (3.31\%), and Chytridiomycota $(0.09 \%)$ (Figure $2 \mathrm{~A})$. By analyzing the fungal communities with a relative abundance greater than $0.3 \%$ on a genus level, we found that Hydnotrya, Tetracladium and Fusarium were the dominant genera, with a relative abundance of $22.35 \%, 6.51 \%$ and $4.01 \%$, respectively, while Humicola had the lowest overall relative abundance (0.31\%) (Figure 2B). The values of the ACE and Chao1 indices in soil were 670.04 and 511.72, and the Shannon and Simpson indices of soil were 5.06 and 0.92 , respectively.

(A)

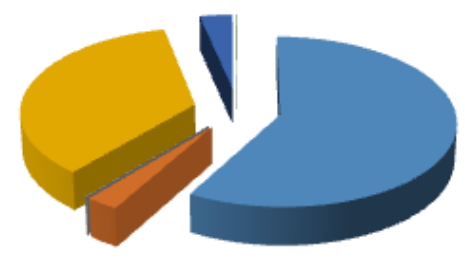

(B)

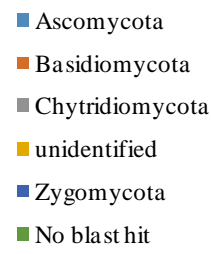

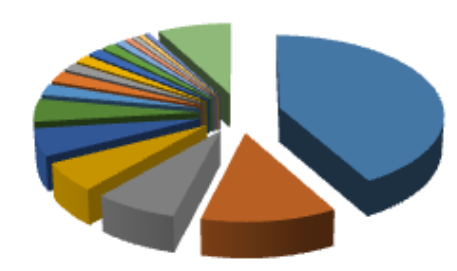

Hydnotrya

- Tetracladium

- Fusarium

- Mortierella

- Aspergillus

- Penicillium

- Alternaria

- Mrakia

Chrysosporium

Hypomyces

- Beauveria

- Acremonium

- Emericellopsis

Thielavia

Pseudogymnoascus

- Humicola

Humico
others

Figure 2. Soil fungal community composition on leaves, at phylum (A) and genus level (B).

\subsubsection{Phyllosphere Fungal Community Diversity and Richness}

As shown in Table 1, C. epigejos had the highest values of the ACE and Chao1 indices among the four grass species (117.25 and 115.05, respectively), while E. dahuricus had the lowest (70.50 and 67.27, respectively). Results showed that C. epigejos had the highest total number of fungi and E. dahuricus the lowest. The Shannon index of I. cylindrica had the highest value (1.66), while C. epigejos had the lowest (0.95). However, the Simpson's Diversity Index of $C$. epigejos had the highest value (0.66) and that of I. cylindrica the lowest (0.30). Thus, C. epigejos had the lowest fungal community diversity and I. cylindrica the highest.

Table 1. Diversity and richness indices of native grass.

\begin{tabular}{cccccc}
\hline Sample & ACE & Chao1 & Shannon & Simpson & Coverage \% \\
\hline Bothriochloa ischaemum & 110.85 & 108.57 & 1.50 & 0.40 & $99.96 \%$ \\
Imperata cylindrica & 104.59 & 107.00 & 1.66 & 0.30 & $99.95 \%$ \\
Elymus dahuricus & 70.50 & 67.27 & 1.10 & 0.58 & $99.98 \%$ \\
Calamagrostis epigejos & 117.25 & 115.05 & 0.95 & 0.66 & $99.94 \%$ \\
\hline
\end{tabular}

As pertains to the phyllosphere fungal communities of the four native grass species investigated, Ascomycota was the dominant phylum and had the highest relative abundance in I. cylindrica, E. dahuricus, C. epigejos and B. ischaemum, with values of 99.12\%, 97.39\%, 99.04\% and 97.83\%, respectively. Basidiomycota was found in the four native grass species with a relative abundance of $0.81 \%, 2.32 \%, 0.10 \%$ and $2.10 \%$, respectively.

On a class level, 12 fungal species were identified in total (Figure 3B). Dothideomycetes was the dominant class in all four native grass species, with relative abundances of $98.08 \%$ (I. cylindrica), 
97.32\% (E. dahuricus), $97.33 \%$ (C. epigejos) and 96.63\% (B. ischaemum). Pezizomycetes was identified in I. cylindrica and C. epigejos; Leotiomycetes was identified in I. cylindrical and B. ischaemum; and Ustilaginomycetes was identified in E. dahuricus and B. ischaemum.

This study analyzed the family and genus of the fungal communities of the four native grass species with a relative abundance greater than $0.1 \%$ (Figure 3C,D). Pleosporaceae (a member of Ascomycota) was the dominant family of the four native grass species and the undetermined fungal families (incertae familiae) in I. cylindric, E. dahuricus, C. epigejos, and B. ischaemum reached $18.81 \%$, $13.05 \%, 12.15 \%$ and $19.24 \%$, respectively. On a genus level, Alternaria spp. was the dominant genus in E. dahuricus, C. epigejos, and B. ischaemum, with relative abundances of $75.06 \%, 80.59 \%$ and $60.44 \%$, respectively. However, the dominant fungal genus in I. cylindric was Amorphotheca spp. (48.40\%). In addition, Cylindrium spp. and Genolevuria spp. were only identified in I. cylindrica; Bjerkandera spp. and Pyrenophora spp. were only identified in E. dahuricus; and Geosmithia spp. and Stemphylium spp. were only identified in C. epigejos. This study found no specific fungal genus in B. ischaemum.

(A)

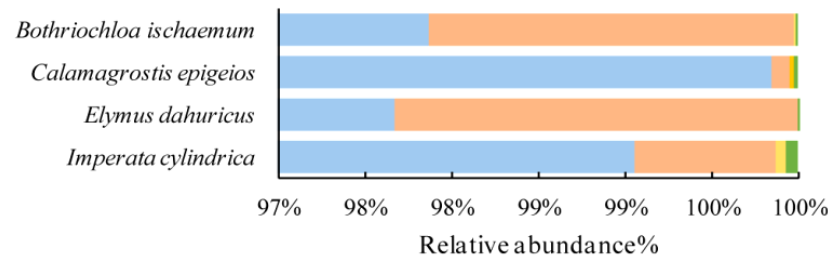

(B)

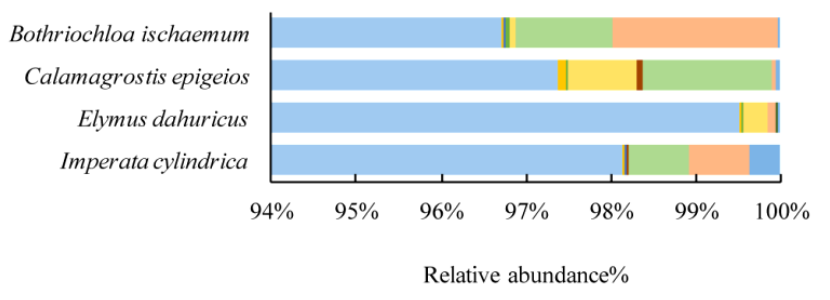

(C)

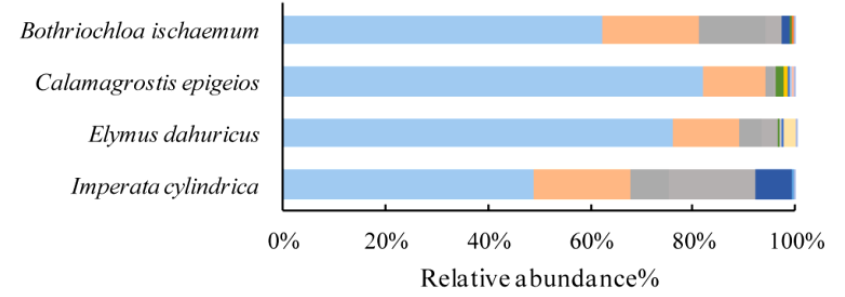

(D)

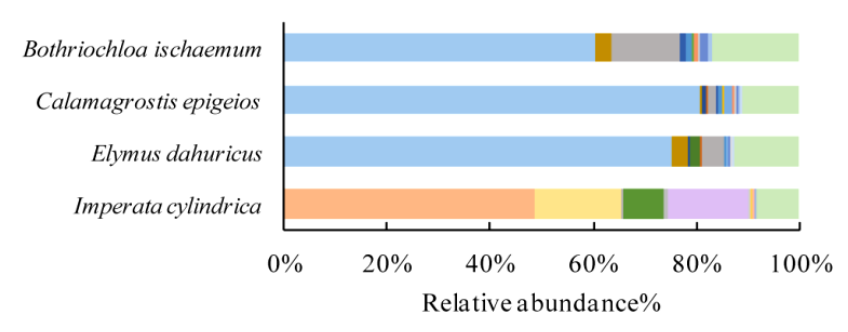

Ascomy cota

- Basidiomycota

=Fungi_Unclassified

- Plantae_Unclassified

-Unclassified

nothers
=Agaricomycetes Cystobasidiomycete Dothideomycetes Eurotiomy cetes Leotiomycetes Microbotry omy cetes Pezizomycetes Saccharomycetes Sordariomycetes Tremellomycetes Ustilaginomycetes Unclassified Others

- Pleosporaceae Unclassified Davidiellaceac Dothioraceae Montagnulaceae Mycosphaerellace Microascacea Nectriaceae Phaeosph

Figure 3. Relative abundance of four native grasses phyllosphere fungi communities at the levels of phylum (A), class (B) and greater than $0.1 \%$ at family (C) and genus (D) levels.

\subsection{Properties of Soil Fungi and the Phyllosphere Fungal Communities in Native Grass Species}

This study analyzed four fungal communities on a phylum level along with soil physicochemical properties using soil PCA, of which the first and second axes explained $71.25 \%$ and $27.39 \%$, respectively 
(Figure 4). We found that Ascomycota was mainly affected by TN and the relative abundance of Basidiomycota was positively correlated to $\mathrm{Cd}$, which can be used as an indicator of $\mathrm{Cd}$ pollution in copper mining areas. In addition, Chytridiomycota was affected by TC, TS and $\mathrm{Cu}$. At the same time, Zygomycota was mainly affected by $\mathrm{pH}$ (Figure 4).

This study used PCoA to analyze the dominant fungal families in the phyllosphere of the four native grass species with a relative abundance greater than $0.1 \%$, for which the first and second axis accounted for $73.34 \%$ and $17.57 \%$, respectively (Figure 5). Results showed that Nectriaceae was closely correlated to (and only identified in) B. ischaemum. Meruliaceae and Phaeosphaeriaceae were closely correlated to (and only identified in) E. dahuricus. In addition, Cordycipitaceae and Sporormiaceae were closely correlated to (and only identified in) C. epigejos.

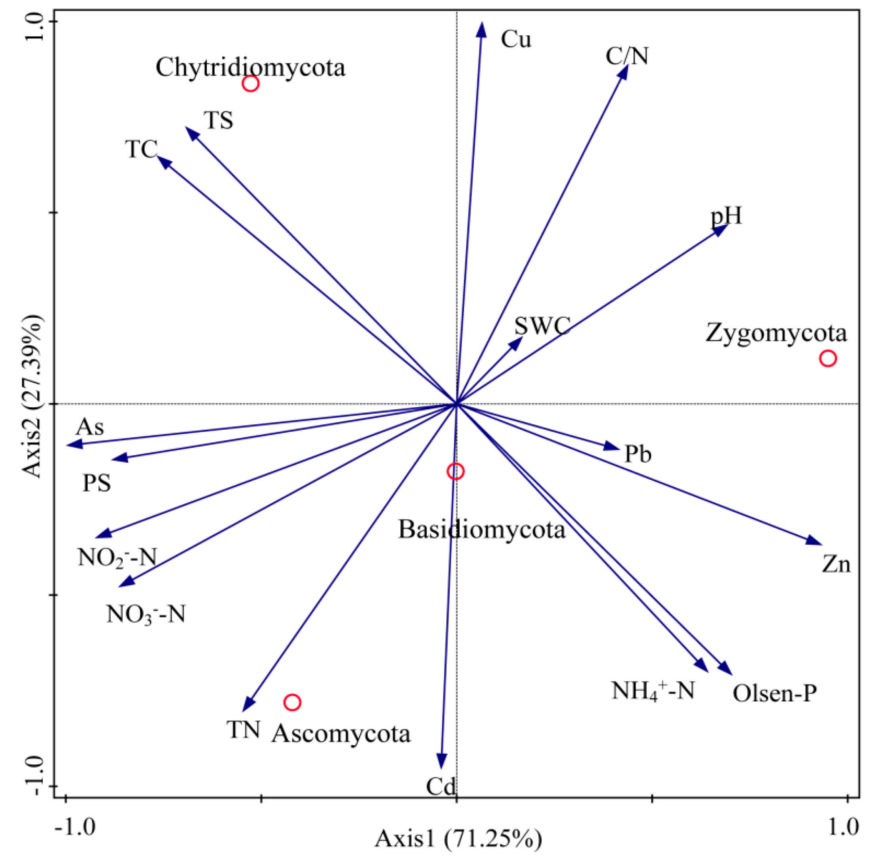

Figure 4. The Principal Component Analysis (PCA) of soil fungi at the levels of phylum and soil physicochemical properties.

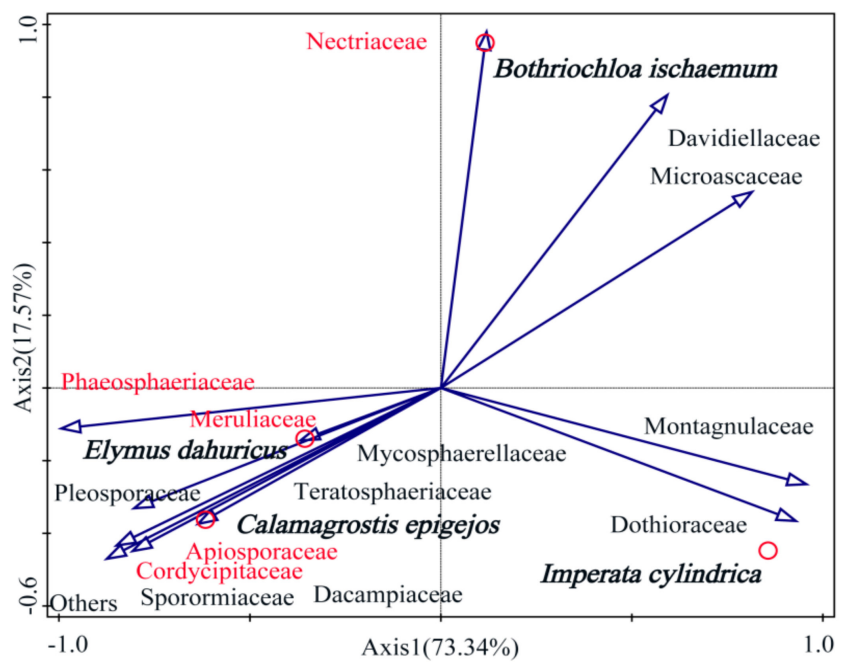

Figure 5. Principal Coordinate Analysis (PCoA) of four native grasses (shown in bold), at family level (the relative abundance greater than 0.001 , and special families in each native grasses were shown in red). 


\subsection{Analysis of Phyllosphere Fungal Communities Using Network Analysis}

This study established a co-occurrence network in order to analyze the relationships among the phyllosphere fungal communities of the four native grass species (Figure 6). The network consisted of 116 nodes and 587 edges and the network diameter and density were 14 and 0.088 , respectively (Table 2). We determined that the coexistence between communities was greater than the exclusion (99.83\%). The network was composed of three phyla, including Ascomycota and Basidiomycota, in the phyllosphere fungal community of the four grass species, which accounted for $87.07 \%$ and $12.07 \%$, respectively, of all species. Moreover, species Erythrobasidiales sp., Rachicladosporium luculiae, and Bjerkandera adusta had the highest betweenness centrality values in the network (Table 3) and they played key roles in maintaining the structure and function of the fungal communities. Therefore, they were the key fungal species of the four native grass species.

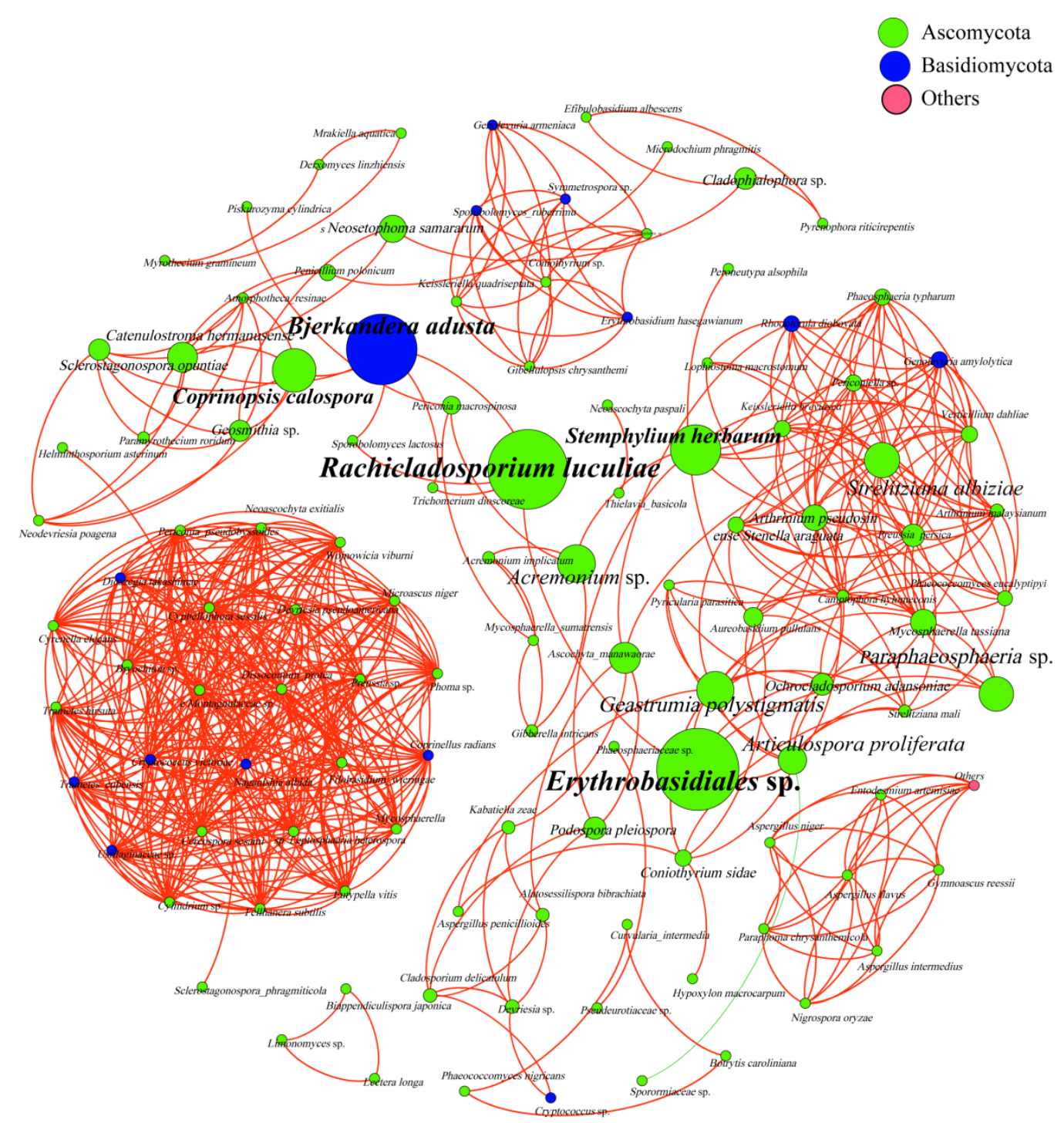

Figure 6. Co-occurrence network of microbial taxa in the four native grasses. Nodes represent fungal species, whereas edges represent positive and negative connections between pairs of species. 
Table 2. Network indices obtained through network analysis from fungal communities of the four native grasses.

\begin{tabular}{|c|c|c|c|c|c|c|c|c|c|c|c|}
\hline Type & Nodes & Edges & Average Degree & Network Diameter & Network Density & Modularity & \multicolumn{2}{|c|}{ Average Clustering Coefficient } & \multicolumn{2}{|c|}{ Average Path Length } & Co-Presence \\
\hline Index & 116 & 587 & 10.121 & 14 & 0.088 & 0.605 & \multicolumn{2}{|r|}{0.788} & & 4.016 & $99.83 \%$ \\
\hline & & & Erythrobasidiales sp. & \multicolumn{2}{|c|}{ Rachicladosporium luculiae } & \multicolumn{2}{|c|}{ Bjerkandera adusta } & \multicolumn{2}{|c|}{ Stemphylium herbarum } & \multicolumn{2}{|c|}{ Coprinopsis calospora } \\
\hline Betw & $\begin{array}{l}\text { Phylu } \\
\text { eenness }\end{array}$ & entrality & Ascomycota & & 672.50 & \multicolumn{2}{|c|}{585.50} & $\begin{array}{c}\text { Ascomycot } \\
387.89\end{array}$ & & \multicolumn{2}{|c|}{$\begin{array}{c}\text { Ascomycota } \\
323.50\end{array}$} \\
\hline
\end{tabular}




\section{Discussion}

Soil nutrient conditions, $\mathrm{pH}$ levels, and heavy metal types and content typically affect the community structure of soil microbes [19]. A large number of studies have reported that soil fungal communities are affected by many environmental factors [20]. Ju et al. [21] found that the most important factors that affect the quantity and diversity of soil fungi in a Taxus chinensis forest in Tianshui City, Gansu Province, China, were soil pH and SWC. In our study, we found that the relative abundance of Zygomycota was affected by soil $\mathrm{pH}$ (Figure 4), which is consistent with results from Ju et al. We found that the order of relative abundance of soil fungi on a phylum level was Ascomycota, having the highest relative abundance, followed by Zygomycota, Basidiomycota, and Chytridiomycota (Figure 2A). The main reason for this could potentially be that most Ascomycota members are saprophytic and therefore the main decomposers in soil. Saprophytic Ascomycota are able to decompose large amounts of refractory organic matter, such as lignin and keratin, and also play an important role in nutrient cycling. Accordingly, Ascomycota were found to be the dominant fungal species in the soil of the tailings dam and they were also the dominant phylum in most soils [22,23].

Some studies reported that $\mathrm{TN}$ and $\mathrm{pH}$ played very important roles in changes of soil fungal community composition and fungi prefer to live in slightly acidic environments [21,24]. In our study, the $\mathrm{pH}$ level of the tailings dam soil was 7.9, which was weakly alkaline. Our results showed that the relative abundances of Ascomycota and Basidiomycota were negatively correlated to soil $\mathrm{pH}$ and the relative abundance of Ascomycota was also positively correlated to TN (Figure 4). In addition, Wang et al. [20] also found that $\mathrm{pH}$ decreased with an increase in TN content; thus, Ascomycota decreased significantly. However, Ascomycota was still the dominant phylum in soil, with the highest relative abundance. The reason for this could potentially be that Ascomycota is significantly affected by TN content. On the other hand, Ascomycota is one of the most abundant fungal phyla, which is able to access nutrition through various means, including saprophytic, parasitic, and symbiotic methods. In addition, $\mathrm{N}$ is the main source for microbial nutrition in soil [25], taking part in the synthesis of proteins, nucleic acids, and macromolecular substances as well as supplying a large number of essential elements for microbial growth and its metabolic processes [26]. At the same time, $\mathrm{N}$ also plays an important role in the material cycle, energy flow, and multi-element balance of ecosystems and its effect on microbial growth exceeds that of soil $\mathrm{pH}$ and other environmental factors [27]. Therefore, Ascomycota can still be the dominant phylum in a weakly alkaline environment. In addition, the $\mathrm{C} / \mathrm{N}$ ratio of soil has been reported to be an important influencing factor of microbial communities [28]. In our study, the $\mathrm{C} / \mathrm{N}$ ratio of soil was 27.41 , and results from PCA showed that the $\mathrm{C} / \mathrm{N}$ ratio of soil was not the main influencing factor for fungi on a phylum level (Figure 4).

The soil of the tailings dam was formed by means of the accumulation of ore sand, which contains a significant amount of heavy metals. According to the third-level of the soil quality standard, soil $\mathrm{Cd}\left(5.27 \mathrm{mg} \cdot \mathrm{kg}^{-1}\right)$ and $\mathrm{Cu}\left(553.53 \mathrm{mg} \cdot \mathrm{kg}^{-1}\right)$ exceeded the standard in this region. The relative abundance of Basidiomycota was positively correlated to $\mathrm{Cd}$ and negatively correlated to $\mathrm{Cu}$. The main reason was that $\mathrm{Cd}$ is a nonessential element for microbial growth. Moreover, heavy metals could promote a certain range of microbial growth before growth is inhibited as concentrations increase [29]. Although both $\mathrm{Cd}$ and $\mathrm{Cu}$ exceeded the standard, $\mathrm{Cd}$ did not reach the maximum concentration of Basidiomycota tolerance and hence still promoted the phylum's growth. Ascomycota, Chytridiomycota, and Zygomycota were not affected by the presence of heavy metals, which could be related to the vast amount of extracellular polymeric substances (EPS) that exist on the surface of fungi. The EPS on the cytoderm of fungi contains a lot of extracellular sugar, protein, fat, and melanin, and active groups (such as sulfhydryl, carboxyl and hydroxyl) can provide the sites necessary for adsorption and the complexing of heavy metals. In this way, most heavy metals will precipitate on the microbial cell wall [30]. In addition, the EPS of fungi also contains a typical metal chelator in the form of oxalic acid, which can immobilize heavy metal ions from forming insoluble oxalate precipitation and reduce the biological toxicity of heavy metals. The tolerance of fungi to heavy metals will therefore ultimately increase [31]. 
Microorganisms play an important role in maintaining the health of leaves and the balance of ecosystems [32,33]. In this study, high-throughput sequencing was used to detect the diversity and richness of phyllosphere fungi residing in four native grass species. According to our study, C. epigejos had greatest number of fungi but I. cylindrical had the greatest fungal diversity (Table 1). We also found that the variation in diversity indices and the quantity in phyllosphere fungal communities were not identical. The main reason for this was that although the habitat of the native grass species was the same, the microenvironment of leaves was not suitable for the growth of all fungal groups and the uniformity of fungi ultimately declined. As a result, C. epigejos had the greatest overall number of fungi but its diversity index was low, which was in accordance with the results reported by Zhuang [34].

Ascomycota was the dominant phylum in the four native grass species as well as the soil, which suggested that this fungal phylum had stronger resistance and environmental adaptability. The main behavior of Ascomycota is saprophytic in both plants and soil. Thus, Ascomycota can decompose most plant and animal residue as well as decompose unusable substances into nutrients that can be directly used by other biota, which are necessary for the function of various substrates. Therefore, Ascomycota became the dominant species in the heavy metal polluted environment of the tailings dam investigated. Nectriaceae, belonging to Ascomycota, has a parasitic and saprophytic behavior pattern and it generally grows in animals and monocotyledons that tend to decline or die or be taken over by other fungal species. At the same time, Nectriaceae also plays a certain role in maintaining the balance of native ecosystems, which functions changed with the environment and host genotypes [35]. In our study, Nectriaceae was only found in B. ischaemum. This was due to the fact that $B$. ischaemum, with its particular growth and development stages, was more suitable for Nectriaceae survival under the environmental sampling conditions of this study. Meruliaceae are widely distributed throughout the world and mostly subsist on rotten wood and litter. The sampling site of this study was in Yuanqu County, Shanxi Province, China, where relatively high temperatures are common. During sample collection, E. dahuricus had entered the seed maturation stage and a few leaves had begun to wither. This type of habitat is suitable for Meruliaceae. Therefore, it had become a special fungal family in E. dahuricus. In China, C. epigejos is a perennial herb and is widely distributed. It contains ergotines, alkaloids, sterols and fatty oils. Sporormiaceae are distributed within a variety of plants and produce secondary metabolites, such as polyketones, terpenes and steroids [36]. In our study, however, the phyllosphere Sporormiaceae community in C. epigejos could produce special secondary metabolites and are therefore unique grass fungi. Thus, it was in accordance with Qiao et al. [37], that is the ability to adapt and the survival in the phyllosphere of different grass species resulted in special fungal communities.

\section{Conclusions}

From our study, we were able to draw the following conclusions. First, Ascomycota was the dominant fungal phylum of the four native grass species, namely, I. cylindrica, E. dahuricus, C. epigejos and B. ischaemum. Second, the soil of the tailings dam had a high $\mathrm{Cu}$ content, and the soil was alkaline. Third, Nectriaceae was the dominant family in B. ischaemum, while Meruliaceae and Phaeosphaeriaceae were only detected in E. dahuricus. Fourth, Cordycipitaceae and Sporormiaceae were only detected in C. epigejos. Fifth, PCA showed that the relative abundance of Basidiomycota was positively correlated to soil Cd; thus, it could be used as an indicator of Cd pollution in soil. Sixth, network analysis showed that Erythrobasidiales sp. played an important role in the community structure and function of the four native grass species. This study provides a scientific basis for screening heavy metal tolerant microbes to improve the efficiency of ecological restoration in mining areas.

Author Contributions: Conceived and designed the experiments: T.J.; performed the experiments: R.W.; analyzed the data: T.J., X.F., R.W.; contributed reagents/materials/analysis tools: B.C. Wrote the paper: T.J., R.W.

Funding: This work was supported by the National Natural Science Foundation of China under Grant No. 31600308, Shanxi Scholarship Council of China under Grant No. 2016-006, and Shanxi Province Science Foundation for Youths under Grant No. 201601D021101. 
Conflicts of Interest: The funders had no role in the design of the study; in the collection, analyses, or interpretation of data; in the writing of the manuscript, and in the decision to publish the results.

\section{References}

1. Men, H.; Li, F.; Ba, L. Research progress of soil microbe in Ningxia. J. Anhui Agric. Sci. 2012, 40, 11264-11267.

2. Liu, D.; Huang, Y.; Sun, H.; An, S. The restoration age of Robinia pseudoacacia, plantation impacts soil microbial biomass and microbial community structure in the loess plateau. Catena 2018, 165, 192-200. [CrossRef]

3. Kezia, G.; Ingo, S.; François, B.; Tesfaye, W. Forest management type influences diversity and community composition of soil fungi across temperate forest ecosystems. Front. Microbiol. 2015, 6, 1300.

4. Intanon, S.; Hulting, A.G.; Myrold, D.D.; Mallory-Smith, C.A. Short-term effects of soil amendment with meadowfoam seed meal on soil microbial composition and function. Appl. Soil Ecol. 2015, 89, 85-92. [CrossRef]

5. Rossi, G.; Beni, C. Effects of medium-term amendment with diversely processed sewage sludge on soil humification-mineralization processes and on $\mathrm{Cu}, \mathrm{Pb}, \mathrm{Ni}$, and $\mathrm{Zn}$ bioavailability. Plants 2018, 7, 16. [CrossRef] [PubMed]

6. Zhang, W.; Xu, J.; Zhang, T. Advancement on soil fungal research. J. Fungal Res. 2005, 3, 52-58.

7. Li, G.; Ma, K. Progress in the study of elevational patterns of soil microbial diversity. Acta Ecol. Sin. 2018, 38, 1521-1529.

8. Ma, J. Research advances in effects of plant on soil microbial diversity. Biotechworld 2016, 2, 24.

9. Bi, J.; He, D. Research advances in effects of plant on soil microbial diversity. Chin. Agric. Sci. Bull. 2009, 9, 244-250.

10. MejíA, L.; Rojas, E.; Maynard, Z.; Svan, B.; Arnold, A.; Hebbar, P.; Samuels, G.; Robbins, N.; Herre, E.A. Endophytic fungi as biocontrol agents of Theobroma cacao pathogens. Biol. Control. 2008, 46, 4-14. [CrossRef]

11. Pan, J.; Hu, Q.; Qi, H.; Zhang, H.; Zhuang, G.; Bai, Z. Advance in the research of phyllospheric microorganism. Acta Ecol. Sin. 2011, 31, 583-592.

12. Ronseaux, S.; Clément, C.; Barka, E. Interaction of Ulocladium atrum, a potential biological control agent, with Botrytis cinerea and grapevine plantlets. Agronomy 2013, 3, 632-647. [CrossRef]

13. Cao, M.; Jia, T.; Jing, J.; Chai, B. Distribution and rDNA-ITS sequence analysis of endophyte symbionts of Bothriochloa ischaemum at a copper tailings site. Acta Pratacult. Sin. 2017, 5, 163-172.

14. Jia, T.; Cao, M.; Jing, J.; Liu, J.; Chai, B. Endophytic fungi and soil microbial community characteristics over different years of phytoremediation in a copper tailings dam of Shanxi, China. Sci. Total Environ. 2017, 574, 881-888.

15. Wang, R.H; Jia, T.; Cao, M.W.; Chai, B.F. Characteristics of soil physicochemical properties and enzyme activities over different reclaimed years in a copper tailings dam. Environ. Sci. 2018, 39, 3339-3348.

16. Schloss, P.D.; Westcott, S.L.; Ryabin, T.; Hall, J.R.; Hartmann, M.; Hollister, E.B; Lesniewski, R.A.; Oakley, B.B.; Parks, D.H.; Robinson, C.J.; et al. Introducing mothur: open-source, platform-independent, community-supported software for describing and comparing microbial communities. Appl. Environ. Microbiol. 2009, 75, 7537-7541. [CrossRef] [PubMed]

17. Chao, A.; Lee, S.M.; Jeng, S.L. Estimating population size for capture recapture data when capture probabilities vary by time and individual animal. Biometrics 1992, 48, 201-216. [CrossRef] [PubMed]

18. Chao, A.; Shen, T.J. Nonparametric estimation of Shannon's index of diversity when there are unseen species in sample. Environ. Ecol. Stat. 2003, 10, 429-443. [CrossRef]

19. Sui, X.; Zhang, R.; Xu, N.; Liu, Y.; Chai, C.; Wang, J.; Fu, X.; Zhong, H.; Ni, H. Fungal community structure of different degeneration deyeuxia angustifolia wetlands in Sanjiang Plain. Environ. Sci. 2016, 37, 3598-3605.

20. Wang, N.; Yu, J.; Chang, Z.; Huang, H.; Gu, K.; Zhang, Z. Responses of fungal community diversity and composition in paddy soils to straw return. Soils 2017, 49, 1115-1120.

21. Ju, T.; Chen, Y.; Chang, C.; An, L. The diversity of soil fungi and its relations with fertility factors in Taxus chinenesis (Pilg.) Rehd community of Xiaolongshan of Tianshui City. Res. Environ. Sci. 2008, 21, 128-132.

22. Yelle, D.; Ralph, J.; Lu, F.; Hammel, K. Evidence for cleavage of lignin by a brown rot basidiomycete. Environ. Microbiol. 2008, 10, 1844-1849. [CrossRef] [PubMed] 
23. Beimforde, C.; Feldberg, K.; Nylinder, S.; Rikkinen, J.; Tuovila, H.; Dorfelt, H.; Gube, M.; Jackson, D.; Reitner, J.; Seyfullah, L.; Schmidt, A. Estimating the Phanerozoic history of the Ascomycota lineages: combining fossil and molecular data. Mol. Phylogenet. Evol. 2014, 78, 386-398. [CrossRef] [PubMed]

24. Wang, M.; Shi, S.; Lin, F.; Jiang, P. Response of the soil fungal community to multi-factor environmental changes in a temperate forest. Appl. Soil Ecol. 2014, 81, 45-56. [CrossRef]

25. Jiang, H.; Yan, W.; Li, X.; Fan, Y. Diversity and community structure of soil fungi in Larix gmelinii Forest. J. Northwest Forest. Univ. 2010, 25, 100-103.

26. Wan, X.; Huang, Z.; He, Z.; Yu, Z.; Wang, M.; Davis, M.; Yang, Y. Soil C: N ratio is the major determinant of soil microbial community structure in subtropical coniferous and broadleaf forest plantations. Plant Soil 2015, 387, 103-116. [CrossRef]

27. Zhang, L.; Duan, Y.; Wang, B.; Wang, W.; Li, X.; Liu, J. Characteristics of soil microorganisms and soil nutrients in different sand-fixation shrub plantations in Kubuqi Desert, China. Chin. J. Appl. Ecol. 2017, 28, 3871-3880.

28. Han, S.; Gao, R.; Li, A.; Ma, H.; Yin, Y.; Si, Y.; Chen, S.; Zheng, Q. Soil microbial community structure of two types of forests in the mid-subtropics of China. Chin J. Appl. Ecol. 2015, 26, 2151-2158.

29. Xing, Y.; Si, Y.; Hong, C.; Li, Y. Impact of long-term heavy metal pollution on microbial community in iron mine soil. Res. Environ. Sci. 2013, 26, 1201-1211.

30. Su, C. Studies on Lead and Cadmium adsorption by exopolysaccharide and extracelluar protein of natural biofilm. J. Jilin Univ. (Sci. Ed.) 2005, 43, 121-125.

31. Wang, L.; Chen, G.; Zeng, G.; Zhang, W.; Chen, Y. Fungal extracellular polymeric substances and their interaction mechanisms with heavy metals. Environ. Pollut. Control 2010, 32, 74-80.

32. Antízar-Ladislao, B.; Lopez-Real, J.; Beck, A.J. Investigation of organic matter dynamics during in-vessel composting of an aged coal-tar contaminated soil using fluorescence excitation-emission spectroscopy. Chemosphere 2006, 64, 839-847. [CrossRef] [PubMed]

33. Baker, C.; Chitrakar, R.; Obulareddy, N.; Panchal, S.; Williams, P.; Melotto, M. Molecular battles between plant and pathogenic bacteria in the phyllosphere. Braz. J. Med. Microbiol. Res. 2010, 43, 698-704. [CrossRef]

34. Zhuang, W. Taxonomy and related studies on the Nectrioid fungi from China. Chin. Bull. Life Sci. 2010, 22, 1083-1085.

35. Gao, L.; Yu, X.; Xue, Y.; Cui, X.; Li, R.; Yang, Q.; Li, S.; Wang, P. Factors affecting the number of soil microbes in the coastal terrace. J. Anhui Agric. Sci. Univ. 2017, 44, 71-80.

36. Yang, B.; Jia, N.; Xiong, P. Review on the Secondary Metabolites from Sporormiella sp. Nat. Prod. Res. Dev. 2016, 5, 810-819.

37. Qiao, S.; Zhou, Y.; Chao, B.; Jia, T.; Li, C. Characteristics of fungi community structure and genetic diversity of forests in Guandi Mountains. Environ. Sci. 2017, 38, 2502-2512.

(C) 2018 by the authors. Licensee MDPI, Basel, Switzerland. This article is an open access article distributed under the terms and conditions of the Creative Commons Attribution (CC BY) license (http://creativecommons.org/licenses/by/4.0/). 